\title{
Pengaruh Pemberian Jus Averrhoa carambola terhadap Penurunan Tekanan Darah pada Lansia Penderita Hipertensi
}

\author{
Putri Aulia Arza ${ }^{1}$, Andri Irawan ${ }^{2}$ \\ ${ }^{1,2}$ Program Studi Gizi, STIKes Perintis Padang, Indonesia \\ Email: tilla.arza@gmail.com
}

\begin{abstract}
The Effect of Averrhoa carambola Juice on Blood Pressure on Elderly Hypertensive Patients. Hypertension, or high blood pressure, is a very common and serious condition that can lead to or complicate many health problems. Solving this problem by nonpharmacologic, it is needed to be developed, for example with consuming star fruit juice. Star fruit (Averrhoa Carambola) is rich in Vitamin C, and contains high levels of potassium and low in sodium which has the effect of lowering blood pressure. This study aimed to determine the effect of star fruit juice to the reduction of blood pressure in elderly hypertensive patients. The study used a pre-experimental study with one group pretest-posttest design with 10 respondents selected by purposive sampling. The results showed that systolic blood pressure in statistical analysis showed that $\mathrm{p}=0.000(\mathrm{p}<0.05)$ means that Hypotheses received or systolic blood pressure between before and after consumption star fruit juice significantly their influence. That the diastolic blood pressure in statistical analysis showed that $\mathrm{p}=0.001 \quad(\mathrm{p}<0.05)$, which means that Hypotheses received or systolic blood pressure between before and after consumption star fruit juice significantly their influence. The result is expected to give any benefit for the society and become one of the solutions to treat the hypertension suffers.
\end{abstract}

Keywords: Averrhoa carambola, Elderly, Hypertension, Star fruit juice

\begin{abstract}
Abstrak: Pengaruh Pemberian Jus Averrhoa carambola terhadap Penurunan Tekanan Darah pada Lansia Penderita Hipertensi. Hipertensi atau dikenal dengan tekanan darah tinggi merupakan penyakit yang umum dan pada kondisi serius dapat menyebabkan berbagai macam masalah kesehatan. Pengobatan alternatif nonfarmakologis perlu dikembangkan seperti mengkonsumsi jus penurun hipertensi salah satunya buah belimbing. Penelitian ini bertujuan untuk mengetahui pengaruh meditasi untuk tekanan darah pada lansia menderita hipertensi. Penelitian menggunakan studi pra-eksperimen dengan one group pretest-posttest desain dengan 20 responden yang dipilih secara purposive sampling. Hasil penelitian menunjukkan bahwa tekanan darah sistolik pada uji statistik menunjukkan bahwa $p=0,000(p<0,05)$ artinya bahwa Ha diterima atau tekanan darah sistolik antara sebelum dan sesudah pemberian jus belimbing terdapat pengaruh secara signifikan. Tekanan darah diastolik pada uji statistik menunjukkan bahwa $p=0,001(p<0,05)$ yang berarti bahwa Ha diterima atau tekanan darah sistolik antara sebelum dan sesudah pemberian jus belimbing terdapat pengaruh secara signifikan. Hasil penelitian ini diharapkan memberi manfaat bagi masyarakat dan merupakan salah satu solusi bagi perawatan penderita hipertensi.
\end{abstract}

Kata kunci: Averrhoa carambola, Lanjut usia, Hipertensi, Jus belimbing

Hipertensi merupakan masalah yang besar dan serius di seluruh dunia, karena prevalensinya yang tinggi dan terus meningkat dari tahun ke tahun, hipertensi juga merupakan penyebab utama timbulnya penyakit kardiovaskuler seperti serangan jantung, gagal jantung, dan stroke. Hipertensi sering diabaikan karena tidak menunjukkan gejala yang dapat dilihat dari luar sehingga disebut the silent killer (Jannah, dkk, 2013).

Pada umumnya penderita hipertensi adalah orang-orang berusia diatas 40 tahun, namun saat ini tidak menutup kemungkinan diderita oleh orang usia muda, sebagian besar hipertensi primer terjadi pada usia 25-45 tahun dan hanya pada $20 \%$ terjadi dibawah usia 20 tahun dan diatas 50 tahun. Hal ini disebabkan karena orang pada usia produktif jarang memperhatikan kesehatan, seperti pola makan dan pola hidup yang kurang sehat seperti merokok (Dhianningtyas, dkk, 2006).

Peningkatan intensitas pelaksanaan Pos Pembinaan Terpadu (Posbindu) yang merupakan salah satu program dari Pusat Kesehatan 
Masyarakat (Puskesmas) membuat perhatian terhadap kalangan usia dewasa tua dan usia lanjut menjadi meningkat pula. Penderita hipertensi diberi terapi obat anti-hipertensi dengan dosis sesuai dengan tingkatan penyakitnya. Jika dosis yang diberikan telah sampai batas maksimal namun tekanan darah belum menurun, maka dilakukan kombinasi terapi dengan beberapa jenis obat. Hal tersebut yang dapat menyebabkan penderita hipertensi enggan untuk mengonsumsi obat hipertensi. Oleh karena itu, perlu ada food based therapy (terapi berbasis pangan) yang dapat menjadi salah satu alternatif untuk meredakan gejala, bahkan menyembuhkan penyakit. Salah satu tanaman yang banyak digunakan oleh masyarakat Indonesia dalam mengatasi penyakit adalah Belimbing Manis (Averrhoa carambola).

Data dari World Health Organization (WHO) menyebutkan hampir 1 miliar orang atau sekitar seperempat dari seluruh populasi orang dewasa di dunia menyandang tekanan darah tinggi dan jumlah ini cenderung meningkat tiap tahunnya. Lebih dari 50 juta orang di Amerika Serikat mengalami hipertensi Beberapa negara lain di Asia, pada tahun 2000 tercatat 38,4 juta orang penderita dan pada tahun 2025 diperkirakan menjadi 67,4 juta orang (Wahyuni, 2008).

Masalah hipertensi di Indonesia merupakan masalah yang serius. Angka prevalensinya cukup tinggi, sekitar 6-15\%, bahkan pada usia 50 tahun keatas angka tersebut mencapai $20 \%$ dan prevalensinya semakin hari semakin meningkat. Dari penduduk Indonesia dewasa, setiap 1000 orang terdapat 74 orang perempuan dan 94 orang laki-laki menderita hipertensi menyebutkan prevalensi pada wanita berumur antara 50-59 tahun sebesar 29\% dan usia di atas 60 tahun sebesar 64,9\% (Fathonah, dkk, 2012).

Menurut Data Riset Kesehatan Dasar (Riskesdas) menyebutkan bahwa prevalensi hipertensi di Indonesia pada tahun 2013 adalah sebesar $25,8 \%$. Terjadi peningkatan prevalensi hipertensi berdasarkan wawancara (apakah pernah didiagnosis nakes dan minum obat hipertensi) dari 7,6\% tahun 2007 menjadi 9,5\% tahun 2013. Prevalensi hipertensi meningkat dengan bertambahnya umur, pada umur 35-44 tahun adalah sebesar 24,8\%, umur 45-54 tahun meningkat menjadi sebesar $35,6 \%$, dan meningkat lebih besar pada umur 55-64 tahun sebesar $45,9 \%$.

Berdasarkan data dari dinas kesehatan Provinsi Jambi, didapatkan data kasus penyakit hipertensi menempati peringkat kedua dari 10 penyakit terbanyak pada tahun 2013 yaitu sebanyak 33.187 kasus. Berdasarkan penelitian Dietary Approaches to Stop Hypertension (DASH) dikatakan untuk menurunkan tekanan darah sangat dianjurkan mengonsumsi makanan yang tinggi kalium dan serat (Chaturvedi, 2009).

Berdasarkan data dari Dinas Kesehatan Kabupaten Kerinci, didapatkan data kasus penyakit hipertensi menempati peringkat ketiga dari 10 penyakit terbanyak tahun 2015 yaitu sebanyak 4.651 kasus. Data penderita hipertensi di Puskesmas Siulak Gedang didapatkan penyakit pertama tertinggi pada tahun 2013 yaitu sebanyak 756 kasus, sedangkan di tahun 2015 kasus hipertensi terjadi peningkatan sebanyak 852 kasus. Desa Pasar Siulak Gedang pada tahun 2015 kasus hipertensi sebanyak 115 kasus.

Hasil penelitian Kuntoro, dkk (2007) diperoleh dalam penelitian tentang Pengaruh Pemberian Jus Buah Belimbing dan Mentimun Terhadap Penurunan Tekanan Darah Sistolik dan Diastolik Penderita Hipertensi, dari 28 responden menunjukkan bahwa adanya pengaruh pemberian jus belimbing ditambah mentimun tehadap penurunan tekanan darah sistolik sebelum perlakuan yaitu $179,57 \mathrm{mmHg}$ sedangkan tekanan darah diastolik sebelum perlakuan yaitu $111,43 \mathrm{mmHg}$, setelah dilakukan pemberian jus belimbing dan mentimun $200 \mathrm{ml}$ selama 14 hari ternyata terjadi penurunan tekanan darah sistolik yaitu $165,36 \mathrm{mmHg}$ sedangkan tekanan darah diastolik 100,07 mmHg. Belimbing mengandung kadar kalium yang tinggi dan natrium rendah, sehingga dapat dikonsumsi oleh penderita hipertensi sebagai salah satu obat untuk penurunan tekanan darah. Adapun yang membedakan penelitian ini dengan penelitian Nistiandani (2010) dan Dwipayanti (2011) yaitu lama pemberian jus yaitu selama 7 hari.

Berdasarkan fenomena yang dijelaskan dalam latar belakang dan disertai oleh data-data terkait maka peneliti tertarik untuk meneliti lebih lanjut tentang "Pengaruh Pemberian Jus Belimbing Manis (Averrhoa carambola) terhadap Penurunan Tekanan Darah pada Lansia Penderita Hipertensi di Desa Pasar Siulak Gedang Kecamatan Siulak Kabupaten Kerinci Tahun 2016.

\section{METODE}

Desain penelitian ini adalah Quasi Eksperiment dengan rancangan One Group Pretest-Posttest yaitu dengan melakukan 
pengukuran tekanan darah sebelum dan sesudah pemberian jus belimbing manis.

Penelitian ini akan dilakukan pada bulan Februari sampai bulan Juni 2016, dengan mengunjungi rumah-rumah sampel yang menderita hipertensi maupun yang ada di Desa Pasar Siulak Gedang Kecamatan Siulak Kabupaten Kerinci. Subjek dalam penelitian ini adalah lansia penderita hipertensi yang ada di Desa Pasar Siulak Gedang Kecamatan Siulak Kabupaten Kerinci. Teknik pengambilan sampel penelitian dilakukan secara purposive sampling yaitu didasarkan pada suatu pertimbangan tertentu yang sesuai dengan kriteria inklusi menderita hipertensi selama minimal enam bulan, tidak dan belum menerima intervensi yang serupa sebelumnya, tidak menderita penyakit lainnya (penyakit jantung, stroke, diabetes mellitus), tidak sedang mengonsumsi obat hipertensi, serta bersedia secara sukarela mengikuti jalannya penelitian dengan menandatangani informed consent sehingga diperoleh jumah sampel sebanyak 10 orang.

Data primer adalah data yang diperoleh langsung oleh peneliti berupa hasil tekanan darah awal dan tekanan darah akhir pada lansia penderita hipertensi sebelum dan sesudah perlakuan yang akan diukur dengan menggunakan Sphygmomanometer dan Stetoskop yang akan dibantu oleh perawat profesional yang ada di Puskesmas Silulak Gedang. Dengan jumlah sampel yang didapat dijadikan data awal sebelum perlakuan, setelah data awal didapatkan maka diberikan perlakuan dengan memberikan jus belimbing manis, sebanyak $200 \mathrm{ml}$ selama 7 hari kepada lansia penderita hipertensi. Pemberian jus belimbing manis diberikan 1 kali sehari. Sedangkan untuk mengetahui apakah sampel menghabiskan jus belimbing manis yang diberikan sesuai permintaan peneliti atau tidak, maka dari itu peneliti langsung menanyakan ke rumah-rumah sampel.

Data sekunder adalah data yang diperoleh peneliti sebagai data penunjang dalam penelitian. Data sekunder diperoleh peneliti dari laporan medical record pasien mengenai jumlah data pasien hipertensi, nama, jenis kelamin, umur, pekerjaan, dan tekanan darah.

Cara membuat jus belimbing manis $200 \mathrm{ml}$ yaitu disiapkan alat-alat dan bahan, cuci buah belimbing hingga bersih, Potong belimbing beberapa bagian dan buang bagian atas belimbing dan isinya, timbang belimbing yang telah dipotong sebanyak 150 gram, masukkan belimbing yang telah dipotong kedalam blender, masukkan madu 10 gram dan air $50 \mathrm{ml}$, tunggu beberapa menit, masukkan belimbing yang telah diblender yang telah tersedia, jus belimbing siap diminum.

Sebagai penunjang keberhasilan penelitian ini, pengukuran tekanan darah di lakukan oleh seorang perawat profesional yang bersedia memeriksa tekanan darah sampel selama penelitian dengan menggunakan Sphygmomanometer dan Stetoskop.

Data tekanan darah dilihat dari hasil perubahan yang terjadi pada tekanan darahsebelum dan sesudah perlakuan yang ditampilkan dalam bentuk tabel. Adapun pengukuran tekanan darah responden dilakukan setiap hari. Setelah 30 menit di berikan jus belimbing manis, tekanan darah sampel di ukur kembali oleh perawat untuk melihat tekanan darah akhir sampel.

Data yang diperoleh untuk melihat pengaruh pemberian jus belimbing manis terhadap tekanan darah pada lansia penderita hipertensi, dilakukan analisis statistik uji T-test beda dua rata-rata (paired sample t-test).

\section{HASIL}

\section{Karakteristik Responden}

Gambaran karakteristik responden berdasarkan tabel 1 di bawah ini, dapat dilihat bahwa lebih dari setengah responden berumur 45-55 tahun $(70 \%)$, yang rata-rata berjenis kelamin perempuan yaitu sebanyak 10 orang $(100 \%)$ dengan bekerja sebagai petani yaitu sebanyak 4 orang $(40 \%)$ dan wiraswasta yaitu sebanyak 4 orang $(40 \%)$.

\begin{tabular}{|c|c|c|}
\hline $\begin{array}{l}\text { Karakteristik } \\
\text { Responden }\end{array}$ & $\mathbf{n}$ & $\%$ \\
\hline \multicolumn{3}{|l|}{ Umur } \\
\hline 45-55 Tahun & 7 & 70 \\
\hline 56-65 Tahun & 3 & 30 \\
\hline \multicolumn{3}{|l|}{ Jenis Kelamin } \\
\hline Perempuan & 10 & 100 \\
\hline \multicolumn{3}{|l|}{ Pekerjaan } \\
\hline IRT & 2 & 20 \\
\hline Petani & 4 & 40 \\
\hline Wiraswasta & 4 & 40 \\
\hline
\end{tabular}

\section{Konsumsi Jus Belimbing Manis}

Pada saat penelitian dilaksanakan, pemberian jus belimbing manis diberikan setiap hari setelah makan pagi dengan berat bersih sebanyak $200 \mathrm{ml}$ yang terbuat dari $150 \mathrm{gr}$ belimbing manis, $50 \mathrm{ml}$ air, dan $10 \mathrm{gr}$ madu. Pada 
hari pertama penelitian sebelum perlakuan diukur tekanan darah awal sampel. Setelah 30 menit di berikan jus belimbing manis, tekanan darah sampel diukur kembali oleh perawat untuk melihat tekanan darah akhir sampel. Selama penelitian semua sampel dapat menghabiskan jus belimbing manis yang diberikan peneliti.

\section{Gambaran Tekanan Darah Lansia sebelum Pemberian Jus Belimbing}

Berdasarkan hasil penelitian pada lansia yang mengalami hipertensi, sebelum pemberian jus belimbing maka didapatkan data sebagai berikut.

Tabel 2. Gambaran Tekanan Darah Lansia sebelum Pemberian Jus Belimbing

\begin{tabular}{llll}
\hline $\begin{array}{l}\text { Tekanan } \\
\text { darah }\end{array}$ & $\mathbf{n}$ & Mean & $\begin{array}{l}\text { Standar } \\
\text { deviasi }\end{array}$ \\
\hline Sistolik & 10 & 175 & 11.785 \\
Diastolik & 10 & 92 & 6.325 \\
\hline
\end{tabular}

Dapat dilihat bahwa 10 orang lansia yang mengalami hipertensi didapatkan rata-rata tekanan darah sistolik sebelum dilakukan pemberian jus belimbing adalah $175 \mathrm{mmHg}$ dengan standar deviasi 11,785. Rata-rata tekanan darah diastolik sebelum dilakukan terapi meditasi adalah 92mmHg dengan standar deviasi 6,325.

\section{Gambaran Tekanan Darah Lansia Setelah Pemberian Jus Belimbing}

Berdasarkan hasil penelitian pada lansia yang mengalami hipertensi, setelah pemberian jus belimbing maka didapatkan data sebagai berikut.

Tabel 3. Gambaran Tekanan Darah Lansia setelah Pemberian Jus Belimbing

\begin{tabular}{llll}
\hline $\begin{array}{l}\text { Tekanan } \\
\text { darah }\end{array}$ & $\mathbf{n}$ & Mean & $\begin{array}{l}\text { Standar } \\
\text { deviasi }\end{array}$ \\
\hline Sistolik & 10 & 135.00 & 8.498 \\
Diastolik & 10 & 79.00 & 3.162 \\
\hline
\end{tabular}

Pengaruh Pemberian Jus Belimbing Manis Terhadap Tekanan Darah

Untuk melihat pengaruh pemberian jus belimbing manis terhadap tekanan darah, maka digunakan analisa statistik yaitu uji T-test beda dua rata-rata (Paired sample t-test) dapat dilihat pada tabel 4 .
Tabel 4. Pengaruh Pemberian Jus Belimbing ManisTerhadap Tekanan Darah

\begin{tabular}{lcrc}
\hline Pengukuran & n & Mean \pm Stdev & p-value \\
\hline Sistolik & 10 & $175 \pm 11.785$ & 0,000 \\
& 10 & $135.00 \pm 8.498$ & \\
Diastolik & 10 & $92 \pm 6.325$ & 0,001 \\
& 10 & $79.00 \pm 3.162$ & \\
\hline
\end{tabular}

\section{PEMBAHASAN}

Sebelum mengkonsumsi jus belimbing dapat dilihat bahwa 10 orang lansia yang mengalami hipertensi didapatkan rata-rata tekanan darah sistolik sebelum dilakukan pemberian jus belimbing adalah $175 \mathrm{mmHg}$ dengan standar deviasi 11,785. Rata-rata tekanan darah diastolik sebelum dilakukan terapi meditasi adalah 92mmHg dengan standar deviasi 6,325. Berdasarkan hasil wawancara dilapangan oleh peneliti, tingginya tekanan darah pada responden umumnya terjadi karena faktor stres, kurang olahraga, tidak bisanya mengontrol makanan seperti konsumsi garam dan lemak yang berlebihan, konsumsi sayur dan buah yang rendah kegemukan dan bahkan karena faktor genetik atau keturunan.

Kebiasaan makan ini berlawanan dengan teori. Berdasarkan penelitian Dietary Approaches to Stop Hypertension (DASH) dikatakan untuk menurunkan tekanan darah sangat dianjurkan mengkonsumsi makanan yang tinggi kalium dan serat (Chaturvedi, 2009).

Tekanan darah akhir setelah perlakuan mengalami penurunan sebanyak $(87 \%)$ dengan tekanan darah rata-rata $135 / 79 \mathrm{mmHg}$. Hal ini disebabkan pengaruh kandungan jus buah belimbing manis terhadap tekanan darah terlihat jelas dalam peranan kalium, kalsium dan magnesium terhadap pompa kaliumnatrium. Kalium berperan dalam menjaga kestabilan elektrolit tubuh melalui pompa kalium-natrium. Kurangnya kadar kalium dalam darah akan mengganggu rasio kaliumnatrium sehingga kadar natrium akan meningkat yang menyebabkan pengendapan kalsium pada persendian dan tulang belakang yang meningkatkan kadar air tubuh sehingga meningkatkan beban kerja jantung dan penggumpalan natrium dalam pembuluh darah. Pembuluh darah yang terkikis dan terkelupas pada akhirnya menyumbat aliran darah sehingga meningkatkan resiko hipertensi dan dengan terapi jus buah belimbing manis hal ini kemungkinan dapat dihindari. Magnesium sendiri disini berperan dalam mengaktifkan pompa kalium-natrium yang memompa natrium 
keluar dan kalium masuk ke dalam sel (Julianti dalam Artalesi dkk, 2012).

Hasil penelitian Artalesi, dkk, (2012) didapatkan sebagian besar responden pada penelitian ini menyatakan bahwa mereka mendapat ketenangan setelah mendapat terapi jus buah belimbing manis dan ada yang menyatakan tubuh lebih terasa segar serta sakit kepala dan ketegangan otot pada tengkuk yang mereka alami berkurang bahkan hilang, hal ini menunjukkan bahwa kandungan jus buah belimbing manis yang dikonsumsi dapat mengurangi risiko terkena hipertensi dengan membantu mengurangi ketegangan otot dan emosional responden. Hasil penelitian ini menunjukkan bahwa mengonsumsi jus buah belimbing manis berpengaruh atau memiliki efek yang positif terhadap tekanan darah. Hasil penelitian ini dapat disimpulkan bahwa terapi jus buah belimbing manis terbukti mempengaruhi beban kerja jantung, pompa kalium-natrium dan meningkatkan produksi urin serta mendatangkan ketenangan yang pada akhirnya berpengaruh terhadap tekanan darah. Terapi jus buah belimbing manis efektif untuk menurunkan tekanan darah atau mengontrol tekanan darah agar tetap stabil pada pasien dengan hipertensi primer. Hasil penelitian Nistiandani (2010) menyatakan bahwa pengaruh signifikan pemberian jus belimbing terhadap penurunan tekanan darah pada klien hipertensi di wilayah kerja Puskesmas Paleran Kecamatan Umbulsari Kabupaten Jember. Pada penelitian yang dilakukan oleh Dwipayanti (2011) menyatakan bahwa adanya penurunan nilai rata-rata MAP post test penderita hipertensi (responden) telah sesuai dengan teori yang menyatakan bahwa buah belimbing dapat dimanfaatkan untuk menurunkan tekanan darah tinggi. Sehingga terjadinya penurunan rata-rata sistolik dan distolik ini terjadi oleh karena responden telah diberikan terapi buah belimbing, dan keadaan ini menunjukkan bahwa pemberian terapi buah belimbing efektif untuk menurunkan tekanan darah responden yang menderita hipertensi. Berdasarkan tabel 4 diatas dapat diketahui uji statistik yang dikatakan bermakna jika $p<\alpha$, dengan tingkat kepercayaan sebesar 5\% (0.05). dari hasil analisa statistik uji
T-test beda dua rata-rata diperoleh $p=0.000$ (sistolik). $\quad p=0.001 \quad$ (diastolik). Berarti ada perbedaan penurunan tekanan darah sampel sebelum dan setelah pemberian jus belimbing manis.

Hal ini disebabkan oleh Kalium dalam jus belimbing manis dapat menurunkan tekanan darah dengan menimbulkan vasodilitasi sehingga menyebabkan penurunan retensi perifer total dan meningkatkan output jantung. Konsumsi kalium yang banyak akan meningkatkan konsentrasinya di dalam intraseluler sehingga cenderung menarik cairan dari bagian eksraseluler dan menurunkan tekanan darah (Kusnul, 2012).

Natrium dan kalium merupakan mineral makro yang mempunyai hubungan erat dalam berbagai jaringan tubuh. Dari penelitian yang dilakukan oleh beberapa ahli gizi didapatkan bahwa peningkatan jumlah penderita hipertensi ternyata ada hubungannya dengan perubahan rasio natrium dan kalium dalam makanan yang dikonsumsi (Jannah, dkk, 2013).

\section{SIMPULAN}

Berdasarkan hasil penelitian dapat disimpulkan sebelum dilakukan pemberian jus belimbing rata-rata sistolik tekanan darah lansia $175 \mathrm{mmHg}$ dan rata-rata tekanan darah diastolik 92. Setelah diberikan pemberian jus belimbing terjadi penurunan tekanan darah lansia menjadi rata-rata sistolik $135 \mathrm{mmHg}$ dan rata-rata tekanan darah diastolik $79 \mathrm{mmHg}$. Dari hasil penelitian dapat disimpulkan bahwa terdapat pengaruh pemberian jus belimbing terhadap perubahan tekanan darah pada lansia yang mengalami hipertensi (diperoleh $p=0.000$ (sistolik), $p=0.000$ (diastolik) jika $p<\alpha$, dengan tingkat kepercayaan sebesar $95 \%$.

\section{SARAN}

Hasil penelitian ini diharapkan memberi manfaat bagi masyarakat dan merupakan salah satu solusi bagi perawatan penderita hipertensi.

\section{DAFTAR PUSTAKA}

Artalesi. 2012. Efektifitas terapi jus buah belimbing manis (Averrhoe Carambola Linn) terhadap penurunan tekanan darah pada pasien dengan hipertensi primer.

\section{[Skripsi]. Program Studi Ilmu Keperawatan Universitas Riau.}


Balitbang Kemenkes RI. 2013. Riset Kesehatan Dasar; RISKESDAS. Jakarta: Balitbang Kemenkes RI

Chaturvedi, 2009. Diet DASH. http://health.detik.com/read/2013/02/28/13 5036/2182174/1413/diet-dash

Dhianningtyas, Y., \& Hendrati, L. Y. 2006. Risiko Obesitas, kebiasaan merokok, dan konsumsi garam terhadap kejadian hipertensi pada usia produktif. The Indonesian Journal of Public Health, 2(3), 105-109.

Dwipayanti, P. I. 2011. Efektivitas Buah Belimbing Terhadap Penurunan Tekanan Darah Pada Penderita Hipertensi di Sumolepen Kelurahan Balongsari Kota Mojokerto. Jurnal Keperawatan, 1, 1-12.

Fathonah, S., \& Hernawilly, H. 2012. Perilaku pemilihan obat tradisional untuk menurunkan tekanan darah pada lansia di Kota Bandar lampung. Jurnal Keperawatan. Jurnal Keperawatan, 8(1), 1-9.

Jannah, M., Sulastri, D., \& Lestari, Y. (2013). Perbedaan asupan natrium dan kalium pada penderita hipertensi dan normotensi masyarakat etnik Minangkabau di Kota Padang. Jurnal Kesehatan Andalas, 2(3), 132-136.

Kusnul, Z., \& Munir, Z. 2012. Efek pemberian jus mentimun terhadap penurunan tekanan darah. Prosiding Seminas, 1(2).

Kuntoro, K., Wirjatmadi, B., \& Muniroh, L. 2007. Pengaruh Pemberian Jus Buah Belimbing dan Mentimun terhadap Penurunan Tekanan Darah Sistolik dan Diastolik Penderita Hipertensi. Indonesian Journal of Public Health, 4(1).

Nistiandani, Ana, 2010. Pengaruh pemberian jus belimbing manis (averrhoa carambola linn) terhadap penurunan tekanan darah klien hipertensi di wilayah kerja Puskesmas Paleran Kecamatan Umbulsari Kabupaten Jember. Jurnal Skripsi. Vol 1 No 1 hal 110-117. Ilmu keperawatan, Universitas Jember.

Wahyuni, T. 2008. Hipertensi Tak Terkontrol Merusak Organ Tubuh. www.suarakaryaonline.com. (Diakses pada 10 Desember 2015). 